Economia e Sociedade, Campinas, Unicamp. IE. http://dx.doi.org/10.1590/1982-3533.2021v30n3art12

\title{
Indústrias criativas no Brasil: mapeamento de aglomerações produtivas potenciais e sua contribuição para o desenvolvimento local *
}

\author{
Julia Maria Novaes Dias ${ }^{* *}$ \\ Ana Carolina da Cruz Lima ***
}

\begin{abstract}
Resumo
Partindo-se do pressuposto de que a criatividade é um recurso chave em uma economia baseada no conhecimento, o presente trabalho visa a identificação de áreas com sinais potenciais de aglomerações produtivas relacionadas ao setor criativo no Brasil e sua provável contribuição para o desenvolvimento local. Utilizou-se o método de análise multivariada de agrupamentos para a estimação de grupos de municípios aproximadamente homogêneos em termos de dinamismo e criatividade, empregando-se os microdados dos Censos de 2000 e 2010, do IBGE. Foram encontrados três grupamentos principais classificados, respectivamente, como grande polo criativo nacional, polo criativo nacional e polo criativo regional, demonstrando um potencial para formação de aglomerados produtivos do setor. As cidades que formaram tais grupamentos se destacam devido à sua infraestrutura urbana, robustez institucional, governança, presença de mão de obra especializada, posição na hierarquia urbana e proximidade ao eixo mais dinâmico do país.
\end{abstract}

Palavras-chave: Indústrias criativas, Aglomeração, Desenvolvimento regional.

\begin{abstract}
Creative industries in Brazil: mapping potential clusters and their contribution to local development

Based on the assumption that creativity is a key resource in a knowledge-based economy, the current work aimed to identify areas with potential signs of clusters related to the creative sector in Brazil and their likely contribution to local development. The multivariate clustering analysis was utilized to estimate clusters of almost homogeneous municipalities in terms of dynamism and creativity, employing microdata from IBGE's Demographic Census for the years 2000 and 2010. We found three main clusters classified, respectively, as a large national hub, national creative hub and regional creative hub, demonstrating the potential for the formation of productive clusters in the sector. The cities that formed such groups stand out because of their urban infrastructure; institutional robustness; governance; presence of skilled labor; position in the urban hierarchy and proximity to the country's most dynamic region.
\end{abstract}

Keywords: Creative Industries, Cluster, Regional development.

JEL: Z110, R320, R110.

\section{Introdução}

Diante da eclosão de diversos eventos contemporâneos, tais como a intensificação da globalização, o surgimento das novas mídias, a limitação dos modelos econômicos clássicos voltados para os mercados, e o surgimento de modelos que valorizam o conhecimento como ativo estratégico, a Economia Criativa encontrou um terreno amplo para se desenvolver (Reis, 2012). Nesse contexto, a criatividade passa a ser reconhecida cada vez mais como um recurso básico e imprescindível para o desenvolvimento local.

\footnotetext{
* Artigo recebido em 13 de janeiro de 2019 e aprovado em 22 de março de 2021.

** Doutoranda em Economia na Universidade Federal de Minas Gerais (UFMG-Cedeplar), Belo Horizonte, MG, Brasil. E-mail: julianovaesdias@gmail.com. ORCID: https://orcid.org/0000-0003-3340-5752.

${ }^{* * *}$ Professora adjunta do Instituto de Economia da Universidade Federal do Rio de Janeiro (IE-UFRJ), Rio de Janeiro, RJ, Brasil. E-mail: ana.lima@ie.ufrj.br. ORCID: https://orcid.org/0000-0003-4956-8759.
} 
Florida (2005, p. 35, tradução nossa) considera a “[...] criatividade como uma característica humana fundamental e intrínseca. No sentido real, [o autor afirma que] todos os seres humanos são criativos e todos são potencialmente membros da classe criativa" ${ }^{1}$. Portanto, para o autor, o grande desafio do nosso tempo é o de encontrar mecanismos e estratégias para acender a chama criativa dentro de cada indivíduo.

Segundo Taylor (2013), a economia criativa tem se tornado um assunto fortemente ligado ao imaginário da política regional, tornando-se uma temática de destaque no debate acadêmico internacional ao longo dos últimos anos. Dentro de tal contexto, destaca-se que tais indústrias tendem a se organizar em aglomerações produtivas, se beneficiando de sua proximidade por intermédio de reduções de custos, melhorias de qualidade, partilha de força de trabalho e de informação, além de se depararem com um forte potencial para a inovação devido à concentração espacial dos recursos produtivos.

Nessa perspectiva, o objetivo é identificar áreas com sinais potenciais de aglomerações produtivas relacionadas ao setor criativo no Brasil e sua provável contribuição para o desenvolvimento local. Destaca-se que tais atividades tendem a ser intensivas em capital humano (e artístico), inovação, tecnologia, capacidade empreendedora, etc., fatores que tendem a se concentrar em ambientes urbanos e metropolitanos, foco da análise. Para a consecução do objetivo proposto serão estimados modelos multivariados de análises hierárquicas de grupamento para os municípios brasileiros entre 2000 e 2010, o que viabilizará a identificação, por grau de similaridade, de tais áreas.

\section{Revisão de literatura}

Muitas são as divergências entre os conceitos relacionados à Economia Criativa e à temática que a cerca. $\mathrm{O}$ crescente interesse pelo assunto se deu em decorrência da publicação de importantes obras, principalmente a partir dos anos 2000, que traziam o tema para o debate contemporâneo e levantavam diferentes conceitos dentro do estudo da criatividade, tais como "Indústrias Criativas", "Economia Criativa", "Classes Criativas", entre outros.

O conceito de "Indústria Criativa" surgiu em 1994 quando o termo foi utilizado em um Relatório Australiano chamado "Creative nation: commonwealth cultural policy". O tema ganhou maior exposição em 1997 quando governantes no Reino Unido criaram o Grupo de Trabalho das Indústrias Criativas no âmbito do Departamento de Cultura, Mídia e Esporte do Reino Unido (DCMS), com intenção de reposicionar a economia britânica num mundo globalmente competitivo (Nova Scotia, 2012). A partir de então, a designação relativa a essas indústrias se desenvolveu e marcou uma mudança na abordagem de potenciais atividades comerciais que até então eram predominantemente consideradas em termos não econômicos (Oliveira; Araújo; Silva, 2013).

Diversas definições para essas indústrias aparecem na literatura, provindas de estudos de diferentes autores e/ou instituições. Destaca-se o modelo da Conferência das Nações Unidas sobre

(1) O texto em língua estrangeira é: “creativity as a fundamental and intrinsic human characteristic. In a real sense, all human beings are creative and all are potentially members of the Creative Class". 
Comércio e Desenvolvimento (UNCTAD), que é baseado em um conceito amplo de criatividade desde atividades com um forte componente artístico até "[...] qualquer atividade econômica que gere produtos simbólicos com uma forte dependência em propriedade intelectual e para um mercado tão vasto quanto possível" (UNCTAD, 2010, p. 7). Neste modelo não há centralização ou diferença em importância das diversas indústrias.

A "Economia Criativa", por sua vez, pode ser considerada como um somatório das "Indústrias Criativas". Sua concepção remete inexoravelmente à obra de John Howkins, chamada "Creative economy: how people make money from ideas", publicada em 2001. O principal legado do seu trabalho foi o de expandir o conceito de indústrias criativas, acrescentando setores cujos produtos e serviços pudessem ser protegidos por direitos de propriedade intelectual (Corazza, 2013). Howkins (2001) argumentou que produtos e serviços que são passíveis de proteção de propriedade intelectual, tais como música, cinema e filmes, geram mais renda de exportação do que produtos manufaturados. Portanto, no cenário atual em que a manufatura perde importância relativa, o autor incorporou em sua definição a ciência, que está fora do domínio das artes, mas está apta para a devida proteção.

Restrepo e Márquez (2013) chamam a economia da cultura e da criatividade de "Economia Laranja". Os autores partem das diferentes concepções existentes e chegam a uma zona comum a todas elas, que engloba as atividades que: i) possuem a criatividade, arte e cultura como matériaprima; ii) possuem relação com os direitos de propriedade intelectual; iii) possuem função direta em uma cadeia de valor criativa. Eles chamam atenção para as oportunidades que a economia laranja traz para o desenvolvimento dos países na contemporaneidade, em especial aqueles da América Latina e Caribe.

Outro campo de divergências diz respeito às abordagens acerca dos termos "Indústria Cultural" e "Indústria Criativa". Segundo Oliveira, Araújo e Silva (2013), as expressões são às vezes utilizadas indistintamente, porém em outras são consideradas de forma diferenciada. Os autores salientam que os bens e serviços culturais são um subconjunto de uma categoria mais ampla dos bens e serviços criativos. Sendo assim, a Organização das Nações Unidas para a Educação, a Ciência e a Cultura (Unesco) utilizou sua definição da Declaração Universal sobre Diversidade Cultural para delimitar as "Indústrias Culturais", considerando a existência de um ciclo cultural e suas cinco fases: criação, produção, disseminação, exibição/recepção/transmissão e consumo/participação (Cegov, 2017).

Nesse sentido, o Convênio Andrés Bello (CAB) propôs uma metodologia de mensuração da cultura nas economias latinas, a partir da ideia de ciclo cultural da Unesco. Para tal, foram apontadas as diretrizes para a formulação da Conta Satélite da Cultura (CSC), que define o campo cultural como um conjunto de atividades e produtos que existem com o intuito de criar, expressar, interpretar, conservar, e transmitir conteúdos simbólicos (Cegov, 2017).

No Brasil, os esforços para o desenvolvimento de uma conta satélite de cultura partiram do então Ministério da Cultura (MinC). O conceito operacional de cultura foi definido como: "[...] as atividades humanas, compreendidas em sua dimensão econômica, que criam, expressam, interpretam, 
preservam e transmitem conteúdo simbólico na produção de bens e serviços” (Cegov, 2016, p. 24). Além disso, o MinC criou em 2011 a Secretaria da Economia Criativa (SEC) ${ }^{2}$, lançando um plano de gestão (2011-2014) cujo modelo priorizava as indústrias culturais e excluía produtos e serviços ligados à ciência e tecnologia.

O estudo de Firjan (2019) traz um apanhado sobre a situação da indústria criativa no país. O documento salienta que o cenário recessivo dos últimos anos levou a uma estabilização da participação da indústria criativa no Produto Interno Bruto (PIB) brasileiro, percentual que tem se mantido em torno de 2,62\% desde 2014. Em 2017 o PIB criativo do Brasil foi de RS171,5 bilhões, ao passo que, do ponto de vista do mercado de trabalho formal, tal indústria empregou 837,2 mil profissionais naquele ano. Quanto aos ramos ocupacionais, aqueles de consumo e tecnologia empregaram, respectivamente, $43,8 \%$ e $37,1 \%$ dos trabalhadores da indústria no Brasil, apresentando desempenho superior ao observado na economia. Destacaram-se dentro desses núcleos: pesquisa e desenvolvimento (P\&D), tecnologia da informação e comunicação (TIC), publicidade, marketing e arquitetura.

Salienta-se também que, devido ao fato de obterem maior nível de escolaridade, os trabalhadores da indústria possuem um salário médio mensal superior ao do restante dos trabalhadores da economia (RS6.801,00 frente a R\$2.777,00, em 2017) (Firjan, 2019). De acordo com Ruediger et al. (2015), os setores que ofereceram remuneração acima da média em 2013 foram $P \& D$, arquitetura e TIC, respectivamente. Ao passo que os setores que apresentaram vencimentos médios inferiores foram os de moda e expressões culturais.

Além disso, Firjan (2019) faz uma análise territorial dessas atividades econômicas, demonstrando que os estados brasileiros que tiveram a participação da classe criativa superior à média nacional foram São Paulo, Rio de Janeiro (juntos corresponderam a 50\% dos trabalhadores do país), acompanhados por Santa Catarina e Rio Grande do Sul. Segundo os resultados expostos por Ruediger et al. (2015), os 4 estados supracitados foram aqueles que apresentaram os quocientes locacionais do setor criativo (e de tecnologia) acima da unidade, no ano de 2013. Ademais, o estudo também demonstrou que as maiores remunerações se concentraram no Rio de Janeiro, Distrito Federal, São Paulo e Amazonas.

\section{Metodologia e base de dados}

Para identificar áreas com sinais potenciais de aglomerações produtivas relacionadas ao setor criativo no Brasil e sua provável contribuição para o desenvolvimento local, serão utilizados microdados dos Censos Demográficos 2000 e 2010 para estimar modelos multivariados de análises hierárquicas de grupamento. É importante ressaltar o caráter urbano-metropolitano das atividades criativas, assim, a posição de cada localidade na hierarquia urbana também pode condicionar seu

(2) Ressalta-se que o MinC foi extinto em 2019, sendo substituído pela Secretaria Especial da Cultura, subordinada atualmente ao Ministério do Turismo. A pasta ainda contém uma Secretaria Nacional da Economia Criativa e Diversidade Cultural (SECDC), apesar do enfraquecimento das políticas voltadas ao tema. 
desenvolvimento futuro. Portanto, a análise é concentrada nos níveis hierárquicos intermediários e elevados da rede urbana brasileira (até o nível 3B ou $8^{\circ}$ nível da classificação da Região de Influência das Cidades $(\text { REGIC) })^{3}$ ). Além disso, considerou-se apenas as cidades polos das Áreas de Concentração de Pessoas (ACP) ${ }^{4}$, em decorrência do Instituto Brasileiro de Geografia e Estatística (IBGE) não identificar separadamente os municípios de um mesmo ACP em sua classificação REGIC.

A definição dos setores a serem considerados como parte da indústria criativa passa por ampla discussão conceitual, a UNCTAD, então, tornou-se uma importante referência para os pesquisadores da área. Neste estudo optou-se não só pelo uso da definição da UNCTAD ${ }^{5}$ para a classificação de tais segmentos, mas também por adicionar os serviços diversificados e atividades correlacionadas ao agrupamento. Portanto, são considerados além das atividades culturais propriamente ditas, os serviços intensivos em tecnologia e que utilizam a criatividade como insumo ${ }^{6}$.

Vale destacar que as atividades econômicas consideradas foram compatibilizadas com aquelas da Classificação Nacional de Atividades Econômicas (CNAE 2.0) do IBGE, para tornar a aplicação do método viável. Ou seja, optou-se por realizar uma abordagem setorial, em detrimento de uma abordagem ocupacional. De acordo com Oliveira, Araújo e Silva (2013) ${ }^{7}$, enquanto a dimensão setorial dá ênfase ao setor de atuação da empresa (e se este é um setor típico da economia criativa ou não), a dimensão ocupacional foca na ocupação do trabalhador.

O atual estudo fundamenta-se nos critérios utilizados por Machado, Simões e Diniz (2013) e Golgher $(2008,2011)$ para construir os seus próprios indicadores, realizando uma análise descritiva das características socioeconômicas dos municípios brasileiros e a sua consequente capacidade de atração às classes criativas.

Os índices utilizados são descritos na Tabela 1 abaixo.

(3) A classificação REGIC estabelece a hierarquia dos centros urbanos brasileiros, levando em conta a classificação dos centros de gestão do território; a intensidade de relacionamentos; a dimensão da região de influência de cada centro e as diferenciações regionais.

(4) Dentro da classificação REGIC, as cidades que constituem grandes aglomerações urbanas possuem uma particularidade: a unidade de observação considerada na classificação da hierarquia urbana é o conjunto da Área de Concentração da População (ACP).

(5) Atividades consideradas pela UNCTAD como parte da indústria criativa - Herança cultural: expressões tradicionais culturais como artesanato, festivais e celebrações; sítios culturais como sítios arqueológicos, museus, bibliotecas, exibições etc. Artes: artes visuais como pinturas, esculturas, fotografia e antiguidades; artes cênicas como música ao vivo, teatro, dança, ópera, circo, etc. Mídia: publicação e mídia impressa como livros, imprensa e outras publicações; audiovisuais como filmes, TV, rádio e outras transmissões. Criações funcionais: design como moda, gráfico, interiores, joias e brinquedos; nova mídia como vídeo games, softwares, conteúdo criativo digitalizado; serviços criativos como arquitetura, propaganda, $P \& D$ criativo, cultural e recreativo.

(6) A relação das atividades consideradas no escopo do presente trabalho como parte da indústria criativa consta no anexo.

(7) Os autores encontram resultados de maior magnitude na abordagem ocupacional do que naquela setorial. Sendo assim, ressaltase que os dados do presente estudo podem estar subestimando o tamanho da indústria criativa no país. 
Tabela 1

Estatísticas descritivas

\begin{tabular}{|c|c|c|c|c|}
\hline \multirow[b]{2}{*}{ Variáveis } & \multicolumn{2}{|c|}{2000} & \multicolumn{2}{|c|}{2010} \\
\hline & Média & $\begin{array}{l}\text { Desvio } \\
\text { Padrão }\end{array}$ & Média & $\begin{array}{l}\text { Desvio } \\
\text { Padrão }\end{array}$ \\
\hline Taxa de esgotamento sanitário & 0.339 & 0.004 & 0.423 & 0.004 \\
\hline Rendimento médio do trabalho principal & 399.53 & 2.97 & 735.78 & 4.43 \\
\hline Índice de Gini & 0.528 & 0.001 & 0.488 & 0.001 \\
\hline Taxa de Formalidade & 0.222 & 0.002 & 0.355 & 0.002 \\
\hline Taxa de Formalidade do setor criativo & 0.345 & 0.003 & 0.611 & 0.002 \\
\hline Taxa de qualificação superior & 0.011 & 0.000 & 0.027 & 0.000 \\
\hline Taxa de qualificação em nível de pós-graduação & 0.001 & 0.000 & 0.009 & 0.000 \\
\hline Taxa de qualificação superior no setor criativo & 0.095 & 0.001 & 0.169 & 0.001 \\
\hline $\begin{array}{l}\text { Taxa de qualificação em nível de pós-graduação no setor } \\
\text { criativo }\end{array}$ & 0.005 & 0.000 & 0.062 & 0.001 \\
\hline Proporção de pessoal ocupado no setor criativo & 0.043 & 0.000 & 0.056 & 0.000 \\
\hline Taxa de cursos superiores criativos & 0.048 & 0.001 & 0.079 & 0.001 \\
\hline
\end{tabular}

Fonte: Elaboração das autoras a partir dos microdados dos Censos Demográficos 2000 e 2010 do IBGE.

A metodologia aqui aplicada é a análise multivariada de grupamentos, que segundo Mingoti (2007), tem o intuito de dividir os elementos da amostra em grupos, de maneira que as unidades pertencentes ao um mesmo grupo sejam similares entre si - com relação às variáveis nele consideradas - enquanto os elementos em grupos diferentes sejam heterogêneos em relação às mesmas características. Diferentes métricas podem ser utilizadas para a determinação do critério de similaridade entre os elementos do conjunto de dados, como as medidas de distância. A autora destaca que para proceder ao agrupamento dos elementos, é necessário escolher uma medida de similaridade (ou dissimilaridade). No presente trabalho, a medida escolhida a priori foi o quadrado da distância Euclidiana.

Tendo em vista que as técnicas de conglomerados são classificadas entre hierárquicas e não hierárquicas, o presente estudo optou pelo uso das técnicas hierárquicas, com o intuito de identificar possíveis agrupamentos e o valor provável do número de grupos $g$ (já que tal número não está prédefinido). Dentre os vários métodos de agrupamentos hierárquicos existentes, o método escolhido foi o de Ward, que é fundamentado na mudança de variação entre os grupos e dentre os grupos que estão sendo constituídos em cada passo do agrupamento.

O procedimento, também chamado de mínima variância, funciona de modo que em cada passo do algoritmo calcula-se a soma de quadrados dentro de cada grupo. Tal soma é o quadrado da distância Euclidiana de cada elemento amostral em relação ao correspondente vetor de médias daquele conglomerado:

$$
S S_{i}=\sum_{j=1}^{n_{i}}\left(X_{i j}-\bar{X}_{i .}\right)^{\prime}\left(X_{i j}-\bar{X}_{i .}\right)
$$

No qual $n_{i}$ é o número de elementos no conglomerado $C_{i}$ durante o passo $k$ do processo de agrupamento; $X_{i j}$ é o vetor de observações do $j$-ésimo elemento amostral que pertence ao $i$-ésimo 
conglomerado; $\bar{X}_{i}$ é o centroide de $C_{i}$ e $S S_{i}$ representa a soma de quadrados correspondente a $C_{i}$. No passo $k$, a soma de quadrados total (SSR) dentro dos grupos é definida como:

$$
S S R=\sum_{i=1}^{g_{k}} S S_{i}
$$

Onde $g_{k}$ é o número de grupos existentes quando se está no passo $k$.

A distância entre os conglomerados $C_{l}$ e $C_{i}$ é, então, definida como a soma do quadrado entre tais grupos:

$$
d\left(C_{l}, C_{i}\right)=\left[\frac{n_{l} n_{i}}{n_{l}+n_{i}}\right]\left(\bar{X}_{l .}-\bar{X}_{i .}\right)^{\prime}\left(\bar{X}_{l .}-\bar{X}_{i .}\right)
$$

Em cada passo do algoritmo de agrupamentos os dois grupos que minimizam a distância dada na equação (3), são combinados. Segundo Mingoti (2007), no método de Ward as comparações de conglomerados que têm tamanhos diferentes recebem uma penalização dada pelo fator de ponderação $\left[\frac{n_{l} n_{i}}{n_{l}+n_{i}}\right]$. Quanto maiores os valores de $n_{i}$ e $n_{l}$ e a distinção entre eles, maior é a razão de penalização, e consequentemente, maior a distância entre os centroides dos grupos confrontados.

\section{Resultados}

A primeira parte desta seção pretende delinear padrões regionais específicos ${ }^{8}$ para os municípios brasileiros, com o propósito de apresentar um desenho geral das suas condições socioeconômicas entre 2000 e 2010, identificando as áreas com melhores indicadores (mais dinâmicas), bem como a importância relativa do setor criativo em tais localidades. Posteriormente, serão estimados modelos de grupamento hierárquico a-espacial, com o intuito de criar uma tipologia regional para as indústrias criativas no Brasil. Tal procedimento viabilizará o mapeamento e a identificação de localidades com potenciais aglomerações produtivas no setor criativo no Brasil.

\section{Rendimento médio do trabalho principal}

Florida (2005) utiliza índices de rendimento regional para examinar a geografia do talento. $\mathrm{O}$ autor utiliza variáveis como renda per capita e variação na renda absoluta, para verificar os efeitos do talento nas características das economias regionais. Espera-se que a presença de mão de obra especializada, que possui salários mais elevados, aumente a renda média do município. Estudos como o da Firjan (2019) corroboram tal expectativa, ao ressaltar que os profissionais criativos possuíam em 2017 um rendimento médio mensal de $\mathrm{R} \$ 6.801,00^{9}$, enquanto a média dos trabalhadores brasileiros (incluindo todos os setores da economia) era de $\mathrm{R} \$ 2.777,00$, pouco mais do que um terço daquela recebida pelos trabalhadores criativos.

A Figura 1 ilustra a distribuição espacial das diferentes faixas de renda no Brasil. A média brasileira para o rendimento do trabalho principal era de $\mathrm{R} \$ 399,53 \mathrm{em} 2000$, enquanto a mesma era

(8) A descrição formal dos índices utilizados é apresentada em anexo.

(9) Vale ressaltar que os dados utilizados pelos autores são da RAIS que considera apenas o mercado formal de trabalho (enquanto os dados dos CENSOS - utilizados na presente pesquisa - consideram também o mercado informal, puxando então a média da renda do trabalho para baixo). 
de $\mathrm{R} \$ 735,78$ no ano de 2010, ambas abaixo do salário-mínimo vigente em 2016 de R $\$ 880,00$ (já que os valores estão atualizados para esta data).

O aumento da renda da população alcançado no período analisado é evidente no mapa abaixo, tendo se concentrado principalmente no eixo centro-sul do país e em alguns municípios da região norte. Essa tendência está diretamente relacionada à política de valorização real do salário-mínimo, que perdurou durante o período analisado.

Figura 1

Rendimento médio do trabalho principal (Brasil, 2000/2010)

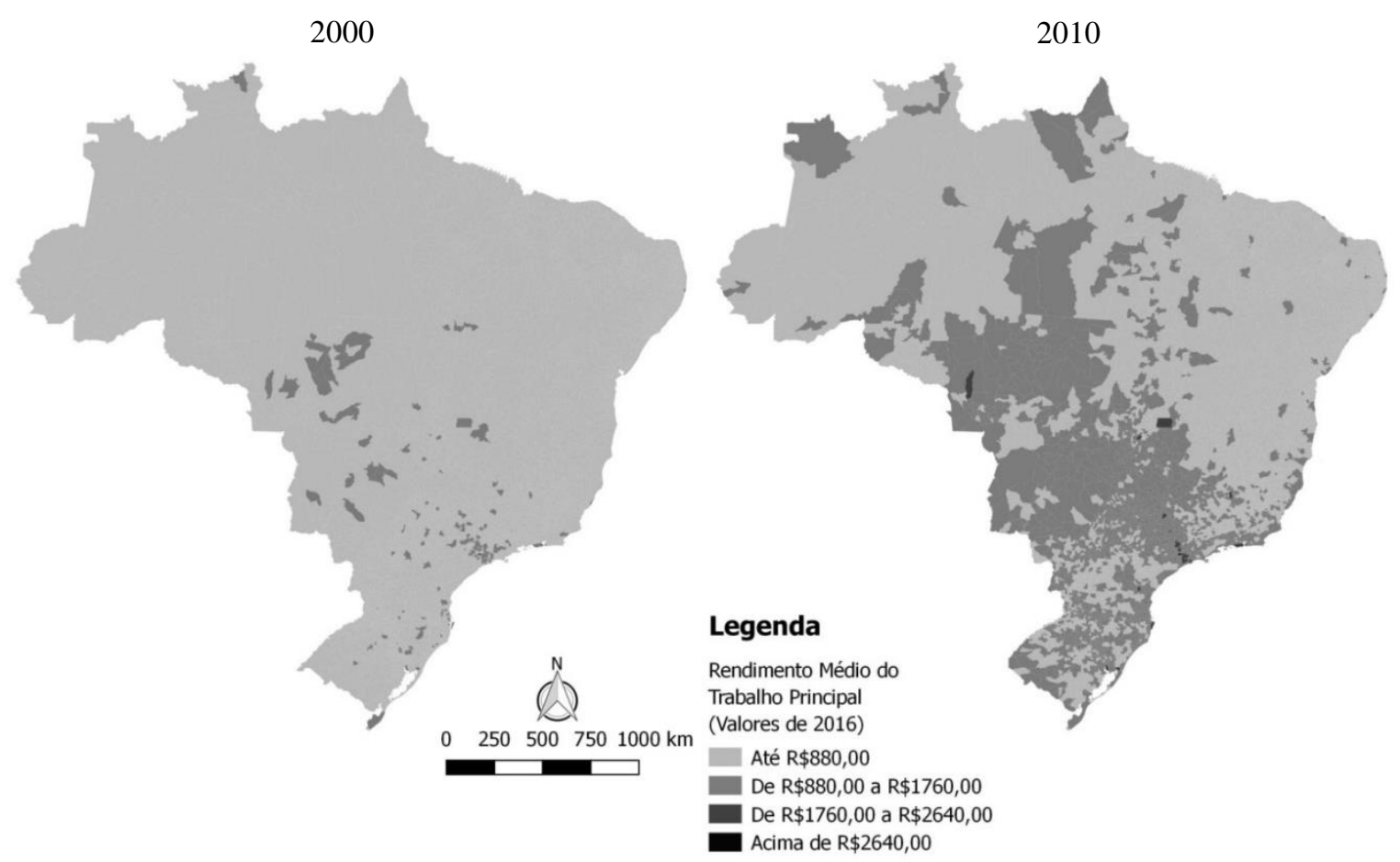

Fonte: Elaboração das autoras a partir dos microdados dos Censos Demográficos 2000 e 2010 do IBGE.

\section{Índice de Gini}

O índice de Gini é uma proxy para a concentração de renda, valores baixos para tal índice representam municípios cuja renda está bem distribuída, o que se torna, consequentemente, um fator aglomerativo para aquela localidade ${ }^{10}$. Verifica-se que o índice do Brasil diminuiu de 0,53 em 2000 para 0,49 em 2010, complementando o resultado anterior e evidenciando o fato de que não só a renda da população aumentou durante o período estudado, mas a sua distribuição também melhorou. Na Figura 2 abaixo é possível observar tal evolução, principalmente na região centro-sul do país, o que pode ser explicado por diversos fatores que ocorreram simultaneamente no período estudado.

(10) A qualidade de vida pode ser considerada um fator de atração para o município. Está representada no presente estudo por maiores taxas de esgotamento sanitário e por uma distribuição de renda mais igualitária. 
O primeiro motivo atribuído por Barros (2007) foi a melhoria na distribuição de renda do trabalho devido a ganhos reais do salário-mínimo, já que ele determina o piso previdenciário e influencia a remuneração de trabalhadores pouco qualificados. Além disso, o autor destaca outros fatores que também contribuíram para tal avanço, como o aumento na cobertura e no tamanho das transferências públicas e transformações no mercado de trabalho (redução da segmentação por gênero e cor, ainda que não muito expressiva).

O trabalho de Barros (2007) além de constatar a diminuição da pobreza em tal período, compara também a efetividade do impacto causado pelas principais políticas adotadas: aumentos no salário-mínimo e programas de transferência de renda - em especial o Programa Bolsa Família (PBF). Ao confrontar as duas políticas para qualquer linha e medida de pobreza, constatou-se que em todas elas o PBF possui uma melhor relação custo-efetividade do que as políticas de valorização do saláriomínimo.

Figura 2

Índice de Gini (Brasil, 2000/2010)

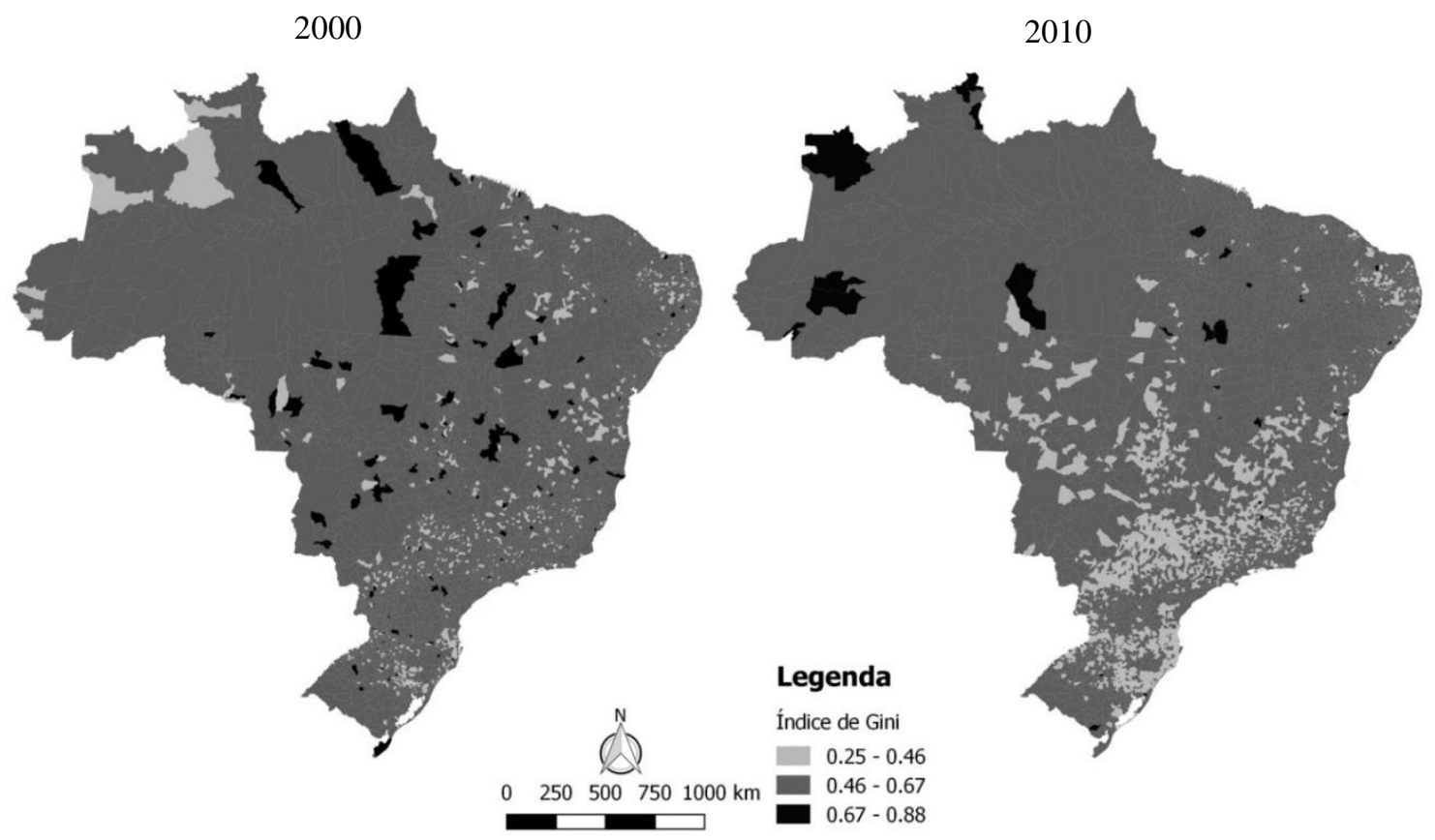

Fonte: Elaboração das autoras a partir dos microdados dos Censos Demográficos 2000 e 2010 do IBGE.

Rocha (2011) atribui o sucesso do Bolsa Família a traços específicos que o programa incorpora, destacando o fato de que pequenas transferências bem focalizadas possuem grande impacto sobre a desigualdade de renda, além de representarem um baixo gasto sobre o PIB. Outro fator diz respeito às "condicionalidades" atreladas a ele, como frequência à escola e cuidados com a saúde, permitindo que se atinjam objetivos de mais longo prazo, rompendo um ciclo vicioso de pobreza. 


\section{Taxa de formalidade}

A formalidade possui um papel importante ao favorecer a dinâmica das atividades criativas, mesmo com a presença significativa da informalidade no setor (principalmente nos estágios iniciais de atividade). No período observado, a média para o indicador no Brasil passou de 22,22\% para $35,48 \%$, apresentando avanços não só na região centro-sul do país, mas também nas regiões Norte e Nordeste.

O setor criativo, especificamente, apresentou taxas de formalidade mais altas do que a média para o total de setores da economia, equivalentes a 34,48\% e 61,14\%, nos anos 2000 e 2010 , respectivamente. O indicador acompanhou o aumento vivido pelos outros setores, e a sua distribuição também abrangeu todo o território nacional (porém de forma mais intensa do que o anterior), como pode ser verificado na Figura 3 abaixo.

Figura 3

Taxa de formalidade no setor criativo (Brasil, 2000/2010)
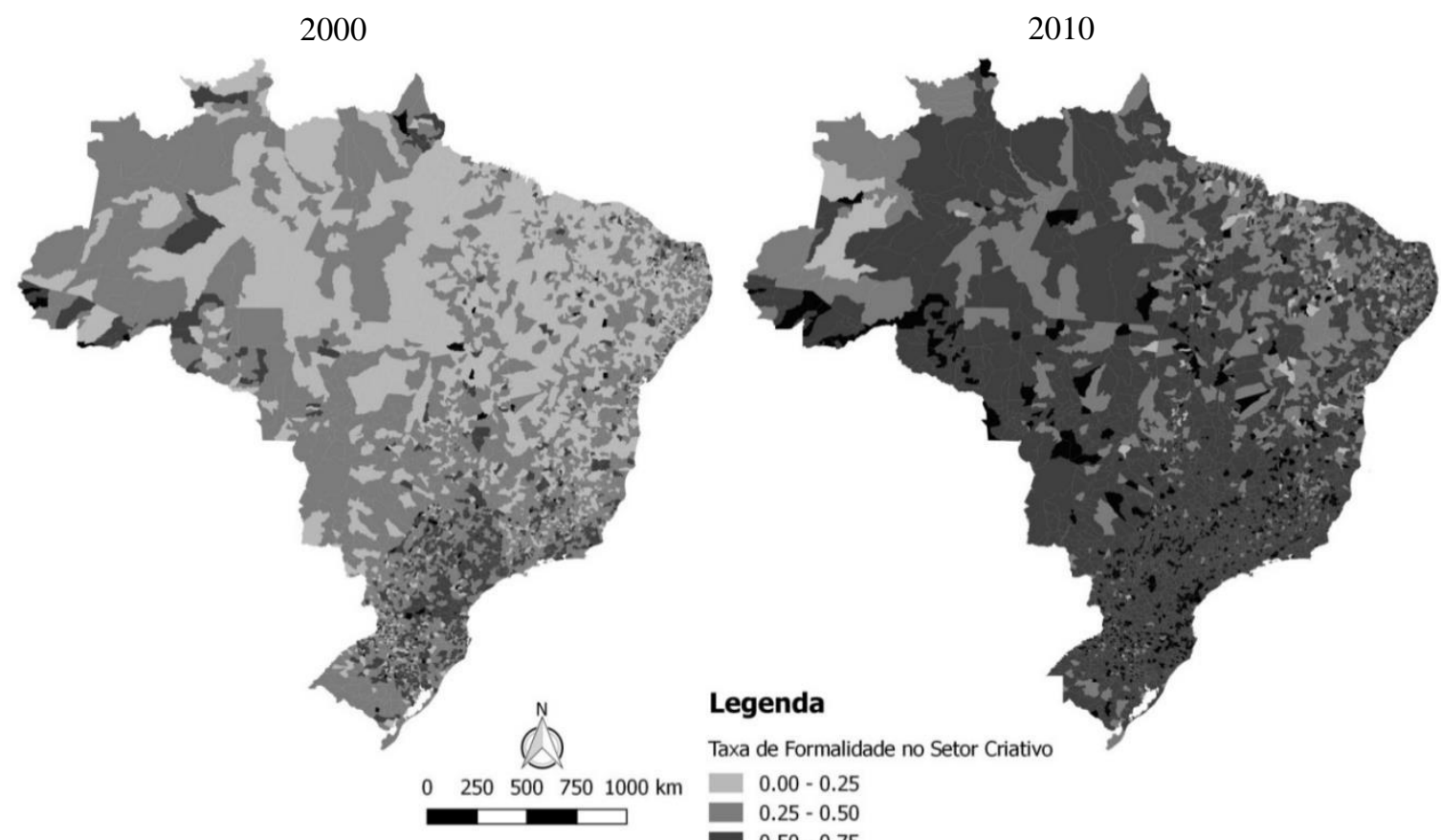

Legenda

Taxa de Formalidade no Setor Criativo

$0.00-0.25$

$0.25-0.50$

$0.50-0.75$

Fonte: Elaboração das autoras a partir dos microdados dos Censos Demográficos 2000 e 2010 do IBGE.

Apesar do aumento da formalidade vivenciado no período considerado, destaca-se uma recente inflexão nessa tendência do mercado de trabalho brasileiro. O estudo de Firjan (2019) atribui o crescimento da informalidade nos últimos anos a mudanças como o avanço das tecnologias e suas novas formas de trabalho, às reformas microeconômicas e ao cenário macroeconômico adverso. Nesse contexto, os autores argumentam que a indústria criativa foi muito impactada pelo processo descrito e que entre 2015 e 2017 houve um aumento de 4,4\% nos trabalhadores autônomos criativos (pessoas jurídicas), frente ao incremento de $0,9 \%$ no total da economia brasileira. 


\section{Indicadores de escolaridade}

Segundo Florida (2005), o nível de escolaridade ${ }^{11}$ dos indivíduos é um fator importante para a caracterização das localidades chamadas criativas. O setor, por ser intensivo em capital humano, requer trabalhadores mais especializados, que possuem um nível de instrução mais alto e que consequentemente são mais produtivos. Por apresentarem tal perfil, tais munícipios são mais dinâmicos e por isso se destacam no cenário nacional.

Machado, Simões e Diniz (2013) utilizam como indicador de educação a proporção de residentes adultos que acabaram o ensino médio. Enquanto Golgher (2008) utiliza o índice de qualificação superior e o índice de qualificação de pós-graduação ${ }^{12}$ para caracterizar os municípios brasileiros. Segundo o autor, os indicadores que abrangem os estudantes e não estudantes em nível de graduação e de mestrado/doutorado são proxys para a qualificação e para a capacidade de inovação, respectivamente, da população de uma cidade.

Os autores supracitados baseiam-se na teoria de Florida (2005), que constrói um índice de talento, compreendendo aquelas pessoas com nível de escolaridade de ensino superior ou mais. O indicador também contempla dados sobre trabalhadores profissionais e técnicos, cientistas e engenheiros. Florida (2005) fundamenta-se na teoria do capital humano, cuja ideia central é a de que a chave para o crescimento regional é a dotação de pessoal altamente qualificado e produtivo.

Nesse mesmo sentido, a educação tem ocupado lugar de destaque também nos estudos de economia do trabalho, que investigam os fatores que influenciam a determinação de salários, tais como os anos adicionais de escolaridade. Silva, Santos e Freguglia (2016) encontram resultados que corroboram a teoria vigente, ao identificar que o retorno à educação no Brasil, por ciclos de escolaridade, foi positivo e significativo em todas as especificações consideradas.

\section{Taxa de qualificação superior no setor criativo}

A média para a taxa de qualificação superior para o Brasil como um todo subiu de $1,10 \%$ para 2,65\% no período estudado, e apesar dos valores serem muito baixos e demonstrarem uma grande necessidade de melhora na educação do país, verifica-se que houve um aumento significativo no período, equivalente a uma variação de $141,16 \%$. Os indivíduos com diploma de curso superior se concentraram na região centro-sul do país.

Já a média para os indivíduos com nível superior no setor criativo é mais alta do que aquela supracitada, sendo igual a 9,52\% para o ano de 2000 e 16,87\% em 2010. Tal resultado corrobora as proposições de Florida (2005) de que o setor criativo atrai pessoas mais qualificadas e que possuem maior probabilidade de inovar e empreender. O que decorre do fato do setor contemplar atividades de alto valor agregado vinculadas aos serviços prestados às indústrias.

O padrão de distribuição territorial para a proporção de indivíduos com qualificação superior em todos os setores da economia e apenas no setor criativo é o mesmo: concentrado na região centrosul do Brasil. Porém, para o segundo grupo, as taxas são mais bem distribuídas dentro dessa região e possuem uma participação mais significativa nos municípios do nordeste (e menos significativa para aqueles da região norte).

(11) Salienta-se que qualificação não é sinônimo apenas de escolaridade formal, todavia, dadas as limitações da base de dados utilizada no presente estudo, apenas essa última será considerada.

(12) O autor também utiliza os índices de qualificação técnica superior e de pós-graduação (ambos levam em conta o nível de escolaridade e as respectivas ocupações) e um índice síntese que é uma combinação dos seus quatro índices de escolaridade. 


\section{Taxa de qualificação em nível de pós-graduação no setor criativo}

A taxa de qualificação em nível de pós-graduação para o Brasil como um todo variou de 0,05\% para $0,90 \%$ entre os anos de 2000 e 2010 e se concentrou na região centro-sul do país (mais especificamente no estado de São Paulo). Já a média para o pessoal ocupado no setor criativo é muito maior, passando de $0,54 \%$ para $6,19 \%$ no período de 10 anos compreendido pelo estudo, apresentando uma variação equivalente a 1046,29\% (Figura 5).

Mais uma vez, as taxas de escolaridade do setor mostram o potencial que a mão de obra criativa possui para torná-lo mais dinâmico e para potencializar o crescimento local. Segundo Silva, Santos e Freguglia (2016), o capital humano acumulado nas cidades amplia a produtividade média dos trabalhadores por meio de spillovers, que possibilitam a troca de experiências e conhecimentos por intermédio das interações em ambientes densos.

Em termos geográficos, o indicador demonstrou uma distribuição mais homogênea do que os anteriores, com exceção da região norte do país, que possui apenas alguns municípios com uma proporção de pós-graduados maior do que $11 \%$ do pessoal ocupado no setor criativo.

Os resultados obtidos tanto para os níveis de qualificação superior quanto para qualificação de pós-graduação corroboram a teoria de que o setor criativo possui trabalhadores mais qualificados e inovadores, por englobar atividades intensivas em capital humano. $\mathrm{O}$ argumento permeia o presente estudo e justifica o uso de tais indicadores na caracterização das cidades e construção das aglomerações criativas.

Figura 4

Taxa de qualificação superior no setor criativo (Brasil, 2000/2010)
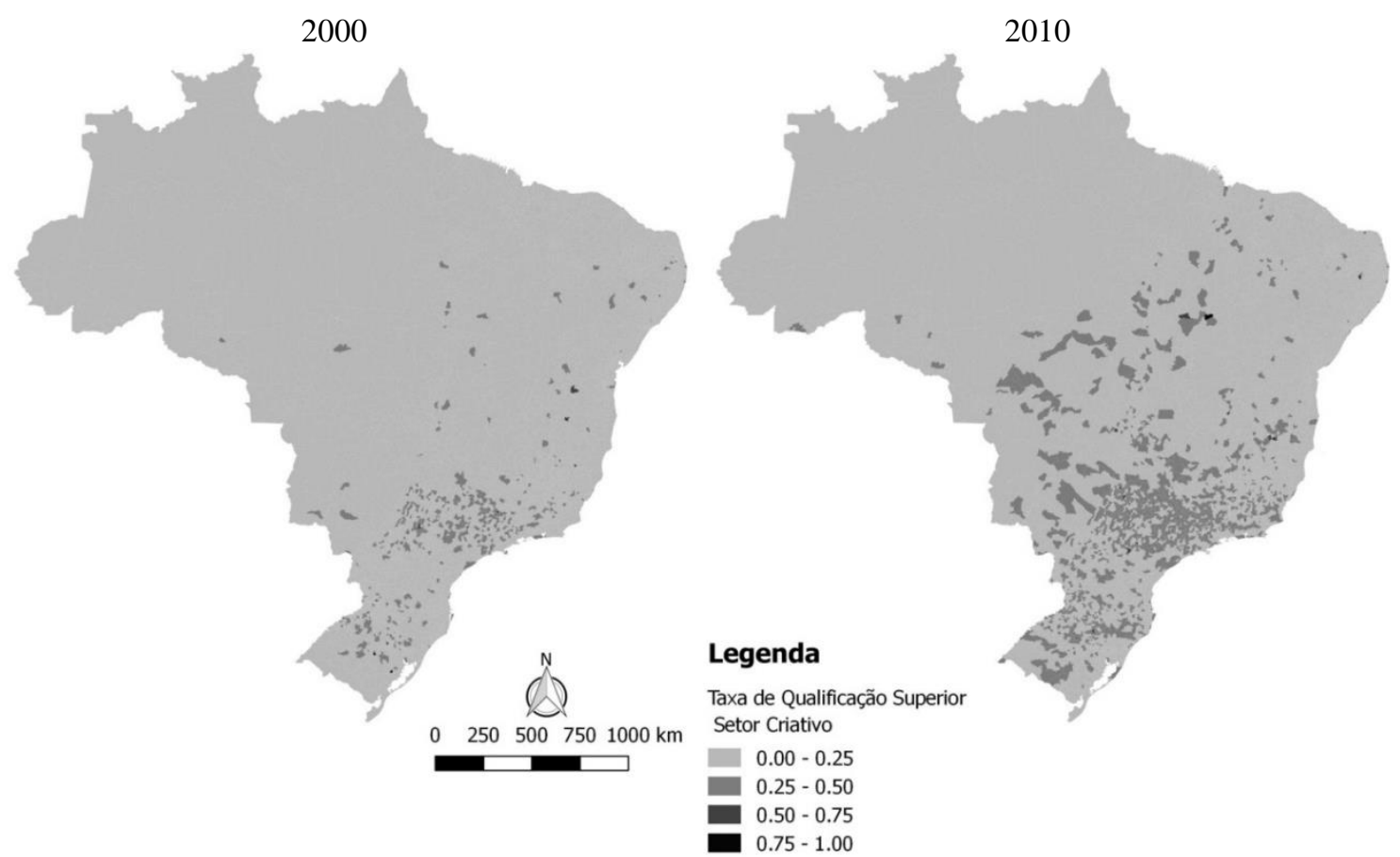

Fonte: Elaboração das autoras a partir dos microdados dos Censos Demográficos 2000 e 2010 do IBGE. 
Taxa de qualificação em nível de pós-graduação no setor criativo (Brasil, 2000/2010)

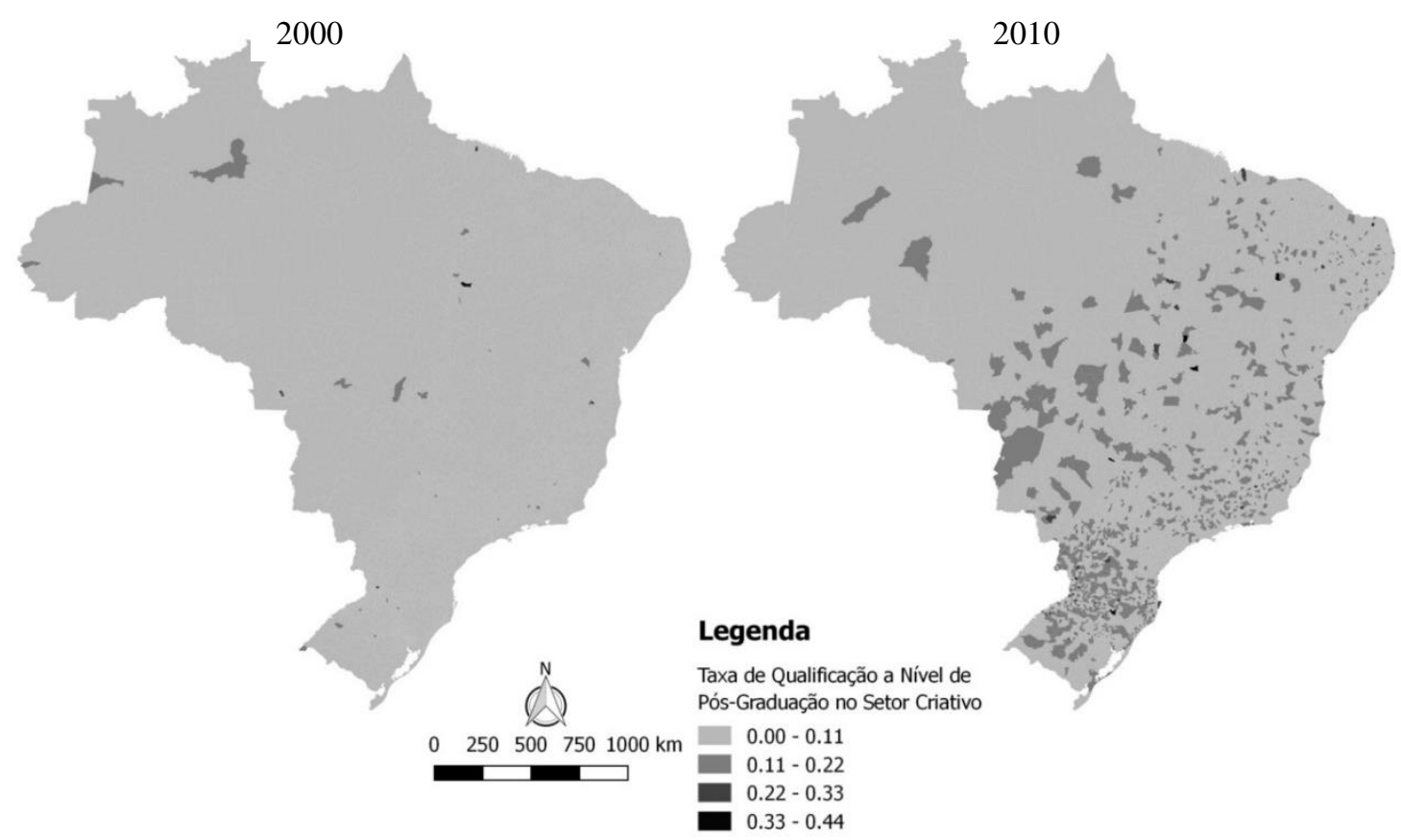

Fonte: Elaboração das autoras a partir dos microdados dos Censos Demográficos 2000 e 2010 do IBGE.

\section{Proporção de pessoal ocupado no setor criativo}

O indicador é tido como uma proxy para a classe criativa assim como em Florida (2005), que ao construir o índice de talento considera não só a qualificação dos indivíduos, mas também a ocupação dos mesmos.

A média brasileira para a proporção de trabalhadores criativos passou de 4,35\% para 5,61\% entre 2000 e 2010. Em termos geográficos, a sua distribuição se concentrou na região centro-sul do país, tendo mudado muito pouco sua configuração ao longo do tempo. Tal concentração deve-se ao fato de o setor exigir amplas economias de escala, além de atividades dinâmicas, intensivas em capital e de maior valor agregado (Figura 6). 
Figura 6

Proporção de pessoal ocupado no setor criativo (Brasil, 2000/2010)

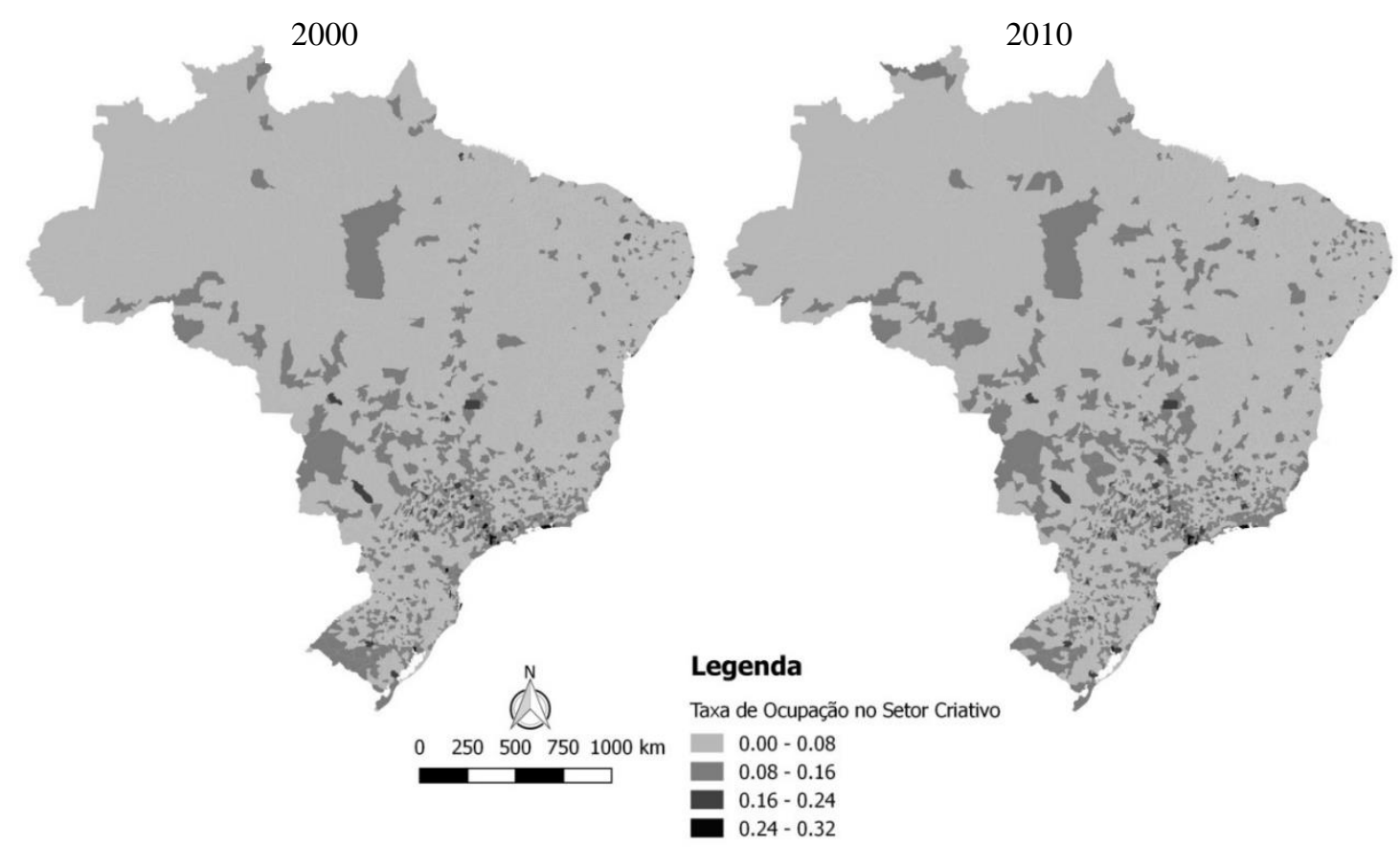

Fonte: Elaboração das autoras a partir dos microdados dos Censos Demográficos 2000 e 2010 do IBGE.

\section{Taxa de cursos superiores criativos}

A taxa média de cursos superiores criativos passou de $4,79 \%$ para $7,86 \%$ no período, revelando que os trabalhadores do setor ainda são pouco especializados em sua área. Como a média de qualificação superior no setor variou de $9,52 \%$ para 16,87\%, conclui-se que apenas metade dos trabalhadores criativos com ensino superior exerce sua área de formação original. Tal resultado pode estar comprometendo diretamente o efetivo potencial do setor, já que o nível de qualificação da mão de obra é um fator tão importante para a produtividade do mesmo (figura 7).

Como na maioria dos índices anteriores, a sua distribuição espacial se concentra na região centro-sul do país, tendo se intensificado no segundo período analisado. 
1Taxa de cursos superiores criativos (Brasil, 2000/2010)

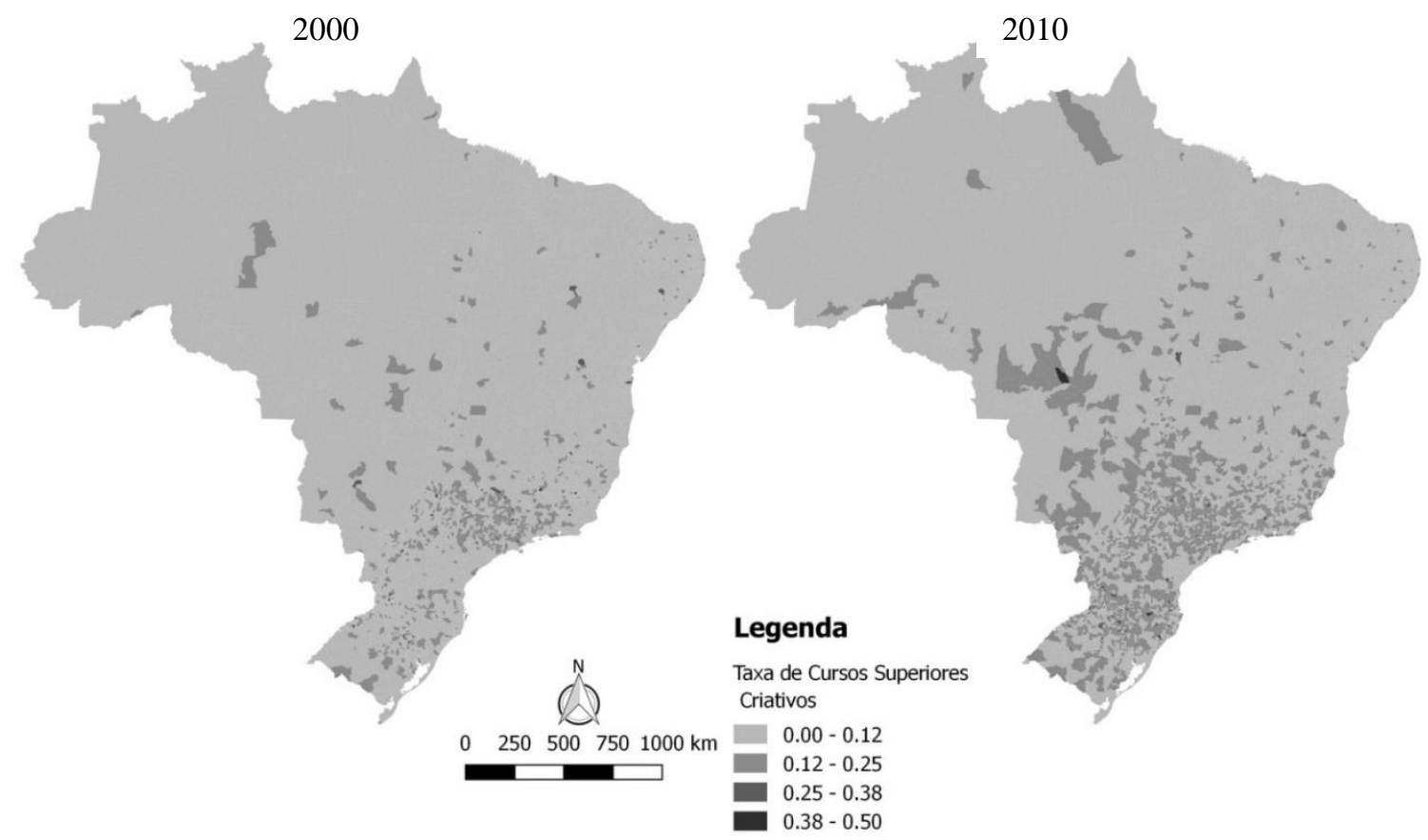

Fonte: Elaboração das autoras a partir dos microdados dos Censos Demográficos 2000 e 2010 do IBGE.

A análise descritiva dos indicadores censitários para o setor demonstra a sua expressiva heterogeneidade, tanto em termos espaciais quanto em determinados índices analisados. Uma vez identificadas essas particularidades e considerando o seu potencial de crescimento, é importante identificar padrões (grupos) mais específicos, que sejam capazes de criar uma tipologia regional para o setor criativo.

Foram estimados modelos de grupamento hierárquico a-espacial, viabilizando-se o mapeamento e a identificação de localidades com potenciais aglomerações produtivas no setor criativo no Brasil. A identificação dessas áreas pode ser considerada um primeiro estágio para a análise espacial mais detalhada do setor, uma vez que a análise estatística não incorpora variáveis relacionadas à robustez institucional, característica fundamental dos aglomerados produtivos.

Para a estimação dos grupos foram utilizadas as seguintes variáveis municipais: taxa de esgotamento sanitário, rendimento médio do trabalho principal, proporção do pessoal ocupado no setor criativo, taxa de formalidade no setor criativo, taxa de escolaridade em nível superior no setor criativo, taxa de escolaridade em nível de pós-graduação no setor criativo, coeficiente de Gini, proporção de pessoal ocupado no setor criativo que possui curso superior em áreas criativas, classificação da região de influência das cidades (REGIC).

As Tabelas 2 e 4 abaixo mostram a quantidade de munícipios presentes em cada um dos grupos estimados e também os percentuais absolutos e acumulados. Já as Tabelas 3 e 5 mostram as médias das taxas supracitadas, equivalentes a cada um deles. As Figuras 8 e 9 apresentadas posteriormente representam a distribuição dos grupos estimados ao longo do território brasileiro e a variação da sua configuração durante o período estudado. 
Tabela 2

Quantidade de municípios em cada grupo (2000)

\begin{tabular}{cccc}
\hline Grupos & Frequência & Percentual & Acumulado \\
\hline 1 & 57 & 23.17 & 23.17 \\
2 & 41 & 16.67 & 39.84 \\
3 & 10 & 4.07 & 43.9 \\
4 & 16 & 6.5 & 50.41 \\
5 & 58 & 23.58 & 73.98 \\
6 & 64 & 26.02 & 100 \\
\hline Total & 246 & 100 & \\
\hline
\end{tabular}

Fonte: Elaboração das autoras a partir dos microdados do Censo Demográfico de 2000 do IBGE.

Tabela 3

Taxas médias para os respectivos grupos (2000)

\begin{tabular}{lcccccc} 
& \multicolumn{7}{c}{ Grupos } \\
\cline { 2 - 7 } Taxas & 1 & 2 & 3 & 4 & 5 & 6 \\
\hline Taxa de esgoto & 0.89 & 0.83 & 0.93 & 0.65 & 0.54 & 0.32 \\
Rendimento médio do trabalho & 876.75 & 702.05 & 1336.32 & 827.18 & 608.28 & 401.25 \\
Taxa de PO do setor & 0.13 & 0.10 & 0.23 & 0.15 & 0.10 & 0.06 \\
Taxa de formalidade do setor & 0.52 & 0.53 & 0.54 & 0.50 & 0.47 & 0.36 \\
Taxa de curso superior no setor & 0.25 & 0.21 & 0.31 & 0.22 & 0.17 & 0.10 \\
Taxa de pós-graduação no setor & 0.02 & 0.01 & 0.03 & 0.02 & 0.01 & 0.01 \\
Coeficiente de Gini & 0.56 & 0.53 & 0.59 & 0.62 & 0.58 & 0.58 \\
Taxa de cursos criativos & 0.14 & 0.12 & 0.19 & 0.12 & 0.08 & 0.04 \\
REGIC & 6.54 & 7.22 & 3.20 & 3.75 & 6.74 & 7.58 \\
\hline
\end{tabular}

Fonte: Elaboração das autoras a partir dos microdados do Censo Demográfico de 2000 do IBGE.

Tabela 4

Quantidade de municípios em cada grupo (2010)

\begin{tabular}{cccc}
\hline Grupos & Frequência & Percentual & Acumulado \\
\hline 1 & 36 & 14.63 & 14.63 \\
2 & 89 & 36.18 & 50.81 \\
3 & 9 & 3.66 & 54.47 \\
4 & 15 & 6.1 & 60.57 \\
5 & 60 & 24.39 & 84.96 \\
6 & 37 & 15.04 & 100 \\
\hline Total & 246 & 100 &
\end{tabular}

Fonte: Elaboração das autoras a partir dos microdados do Censo Demográfico de 2010 do IBGE. 
Indústrias criativas no Brasil: mapeamento de aglomerações produtivas potenciais e sua contribuição para o desenvolvimento local

Tabela 5

Taxas médias para os respectivos grupos (2010)

\begin{tabular}{lcccccc} 
& \multicolumn{7}{c}{ Grupos } \\
\cline { 2 - 7 } Taxas & 1 & 2 & 3 & 4 & 5 & 6 \\
\hline $\begin{array}{l}\text { Taxa de esgoto } \\
\text { Rendimento médio do }\end{array}$ & 0.90 & 0.82 & 0.94 & 0.70 & 0.48 & 0.39 \\
trabalho & 1507.41 & 1247.05 & 2151.38 & 1447.30 & 980.29 & 647.33 \\
Taxa de PO do setor & 0.17 & 0.13 & 0.25 & 0.17 & 0.10 & 0.07 \\
$\begin{array}{l}\text { Taxa de formalidade do } \\
\text { setor }\end{array}$ & 0.68 & 0.67 & 0.67 & 0.67 & 0.64 & 0.55 \\
$\begin{array}{l}\text { Taxa de curso superior no } \\
\text { setor }\end{array}$ & 0.27 & 0.25 & 0.29 & 0.24 & 0.18 & 0.15 \\
$\begin{array}{l}\text { Taxa de pós-graduação no } \\
\text { setor }\end{array}$ & 0.15 & 0.11 & 0.18 & 0.14 & 0.10 & 0.05 \\
Coeficiente de Gini & 0.51 & 0.50 & 0.59 & 0.61 & 0.56 & 0.54 \\
Taxa de cursos criativos & 0.19 & 0.16 & 0.23 & 0.17 & 0.11 & 0.06 \\
REGIC & 6.11 & 7.18 & 2.89 & 3.67 & 6.92 & 7.62 \\
\hline Fonte: Elaborac̃á das autora
\end{tabular}

Fonte: Elaboração das autoras a partir dos microdados do Censo Demográfico de 2010 do IBGE.

Figura 8

Distribuição territorial das aglomerações criativas (Brasil, 2000)

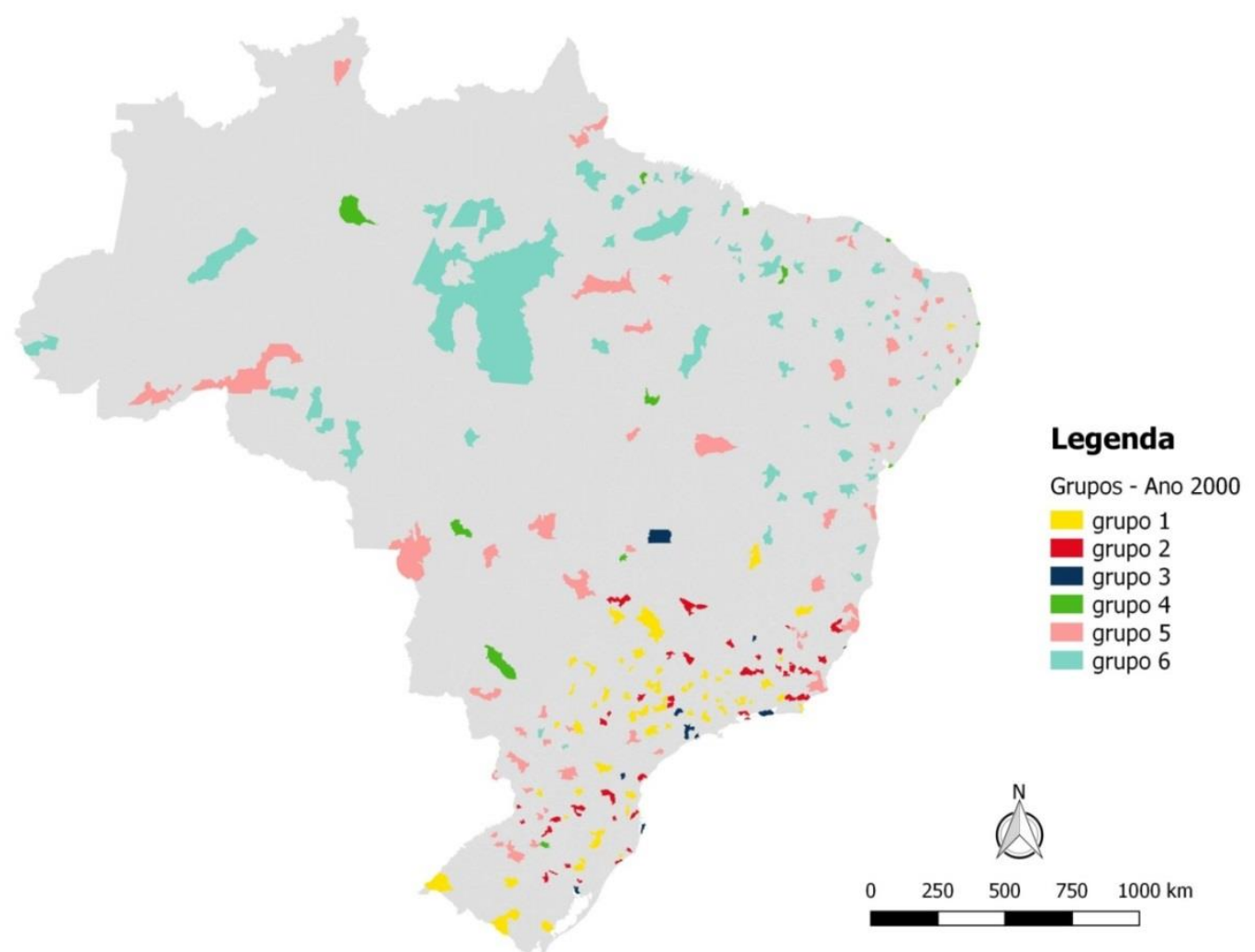

Fonte: Elaboração das autoras a partir dos microdados do Censo Demográfico 2000 do IBGE. 
Figura 9

Distribuição territorial das aglomerações criativas (Brasil, 2010)

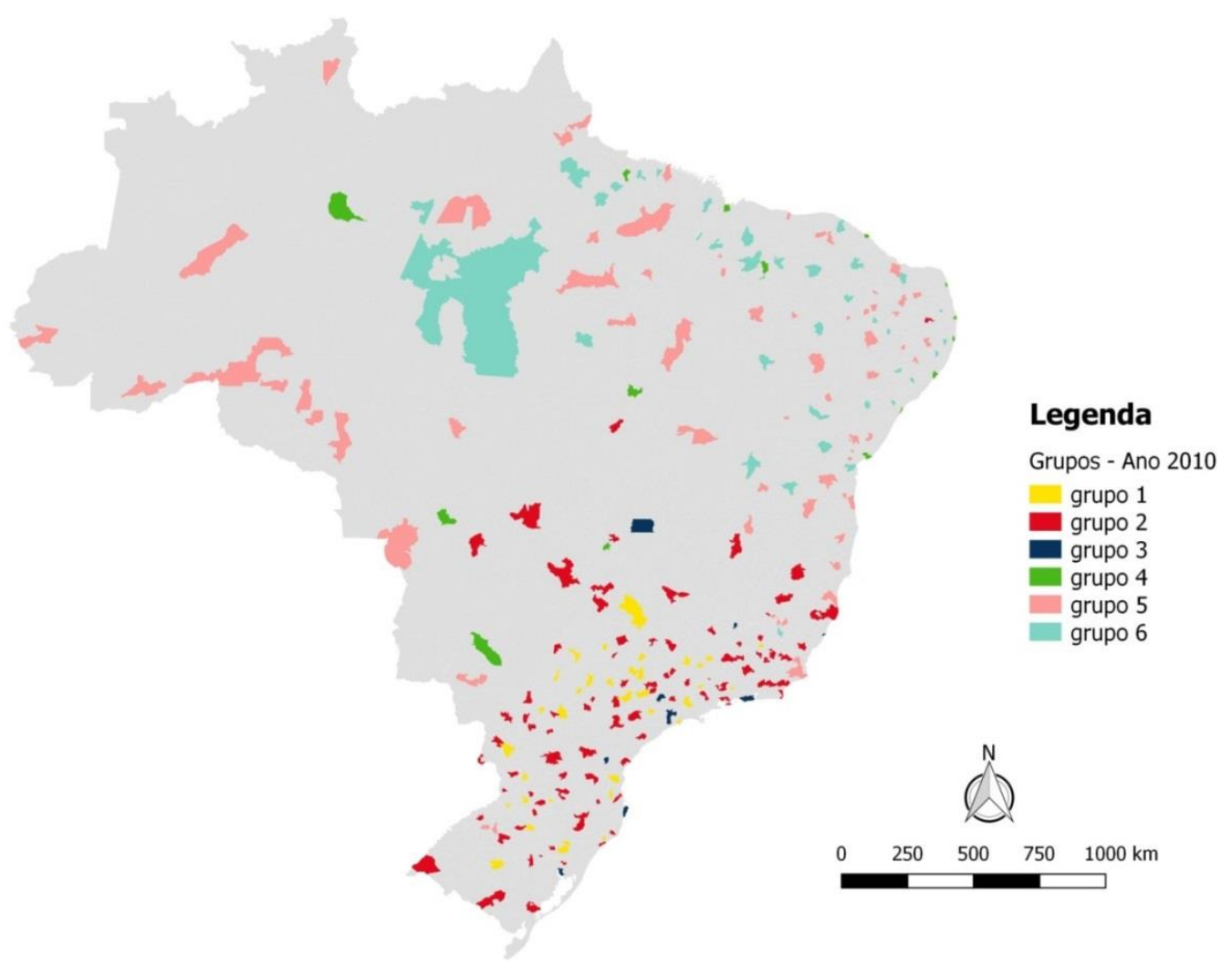

Fonte: Elaboração das autoras a partir dos microdados do Censo Demográfico 2010 do IBGE.

A partir da apresentação dos dados acima, conclui-se que o grupo mais dinâmico foi o grupo 3, que engloba a grande metrópole nacional (São Paulo e sua ACP), as duas metrópoles nacionais (ACP do Rio de Janeiro e ACP de Brasília), as capitais dos estados das regiões sul e sudeste e seus respectivos ACP's (Belo Horizonte, Vitória, Curitiba, Porto Alegre e Florianópolis), duas cidades do interior de São Paulo no ano 2000 (ACP de Campinas e ACP de Santos) e apenas uma delas (ACP de Campinas) no ano 2010.

Tal grupo apresentou os maiores valores para todas as taxas em ambos os anos, exceto para o REGIC (já que o mesmo engloba as cidades mais influentes e, portanto, estão nos primeiros níveis - 1, 2, 3 e 4 - valor médio baixo é considerado positivo) e para o coeficiente de Gini. O mesmo representa o "grande polo criativo nacional", formado por grandes cidades; com escala urbana e seus benefícios; robustez institucional e consequente capacidade de promover a criatividade e potencializar o crescimento local. Nesse sentido, Florida, Adler e Mellander (2016) justificam que as atividades inovativas e as start-ups - que antes tinham uma orientação voltada para o subúrbio agora estão se concentrando em áreas urbanas mais densas, que possuem talento e diversidade para a sua constituição e estão mais propensas a essas atividades. 
Em termos de dinamismo, o próximo grupo que se destacou foi o primeiro, sendo formado por 57 cidades em 2000, passando para 36 em 2010. Os níveis REGIC variaram de 5 a 8 , demonstrando que o mesmo é formado basicamente por municípios do interior dos estados do sul e sudeste, tais como ACP de Uberlândia; Uberaba; Lavras; Viçosa; ACP Volta Redonda - Barra Mansa; ACP de Ribeirão Preto, ACP de São José dos Campos, São Carlos, ACP de Londrina, Pato Branco, ACP de Joinville, Criciúma, Balneário Camboriú, ACP de Caxias do Sul, dentre outros. Tal grupo pode ser classificado como o "polo criativo nacional", caracterizado por se concentrar em cidades médias e com abrangência regional, principalmente. É importante destacar que suas cidades se mostraram mais dinâmicas do que as capitais e municípios mais influentes (na hierarquia urbana) de outras regiões do país.

A exceção para a unanimidade das regiões sul e sudeste no grupo 1 foi para o ACP de Campina Grande, que apareceu na estimação do ano 2000. O motivo provável para a existência do outlier é o fato da cidade possuir a Fundação Parque Tecnológico da Paraíba (PaqTcPB), instituição que age como apoio técnico-administrativo para universidades, agências de fomento à pesquisa, interveniente na captação de convênios e como prestadora de serviços especializados (PaqTcPB, 2018).

No ano 2010, tal grupo se tornou mais homogêneo e as taxas se mostraram não só superiores àquelas do ano 2000, mas também superiores aos outros 4 grupos, por unanimidade. Além disso, é o segundo grupo com o coeficiente de Gini mais baixo, é dinâmico e possui níveis de desigualdade relativamente baixos. Vale destacar que a maioria dos seus municípios possui campus de alguma universidade pública, o que justifica as altas taxas de escolaridade (em nível superior e de pósgraduação) e o seu consequente dinamismo.

O fato do grupo 1 possuir cidades com sedes de grandes universidades brasileiras é um indício de que a governança é um fator chave para a formação de aglomerados produtivos e sua consequente implicação para o desenvolvimento regional. Segundo Florida (2005), a universidade torna-se mais crítica do que nunca como fornecedora de talento, conhecimento e inovação, na era do capitalismo criativo. A universidade cumpre esse papel ao realizar e publicar abertamente pesquisas e educar os seus alunos, gerando novas descobertas e aumentando sua eminência.

O grupo 4 formado pelas capitais dos estados das regiões norte, nordeste e centro-oeste, também apresentou taxas expressivas e pode ser chamado de "polo criativo regional". Os níveis REGIC de tal grupo variaram de 3 a 5, e a única cidade que não seguiu o padrão - de capital de estado - foi Passo Fundo, mas que apareceu somente na estimação de 2000.

Ao comparar tal grupo com aquele formado pelas capitais do sul e sudeste (grupo 3), verificam-se taxas menores de esgotamento sanitário e de distribuição de renda (maior coeficiente de Gini dentre todos os grupos). Ou seja, apesar das cidades do grupo 4 possuírem relativa influência na rede urbana brasileira e, principalmente, nos contextos regionais, como as Regiões Metropolitanas de Recife, Fortaleza, Salvador, Manaus e Belém, o desempenho insatisfatório dos indicadores de qualidade de vida implicam dinamismo inferior do que o verificado em algumas cidades médias de menor importância urbana, mas localizadas no eixo sul-sudeste. Acredita-se que há mais entraves para o crescimento socioeconômico desse grupo e que provavelmente ele é formado por municípios com especialização em setores criativos, com potencial para o desenvolvimento de aglomerações 
produtivas de relevância regional. Outra hipótese é de que seja formado por áreas urbanas já congestionadas, menos atrativas para pessoas e empresas, que podem funcionar como enclaves produtivos, com limitados efeitos de transbordamento espacial.

O grupo 2 foi o quarto grupo em termos de dinamismo, classificado como "região criativa complementar". Sua quantidade de cidades mais do que dobrou entre 2000 e 2010, perdendo um pouco de sua homogeneidade. No ano 2000 tal grupo possuía 41 cidades e os níveis REGIC variavam de 6 a 8, sendo que os municípios eram principalmente do interior do sul e sudeste do país, exceto por Itumbiara. Em 2010, o grupo já possuía 89 municípios e alguns deles com nível 5 no REGIC (além daqueles com nível 6, 7 e 8, como em 2000). As exceções ao eixo sul-sudeste aumentaram, englobando mais duas cidades de Goiás, duas do Mato Grosso e uma da Paraíba.

O grupo é formado basicamente por cidades médias e possui o menor coeficiente de Gini dentre todos analisados. Se comparado com os próximos grupos (5 e 6) que possuem uma média de nível REGIC próxima ou até menor (do que 7,22 e 7,18 em 2000 e 2010, respectivamente), as suas taxas são superiores e, consequentemente, o dinamismo também. Assim como acontece com o grupo 1 , o mesmo se destaca frente a outros que possuem cidades mais influentes na rede urbana (pois se localizam nas regiões sul e sudeste).

O grupo 5 foi aquele que se mostrou mais heterogêneo dentre todos os estimados pelo modelo, sendo também chamado de "região criativa complementar". O mesmo englobou os níveis REGIC de 5 a 8 e o número de cidades variou de 58 para 60 entre 2000 e 2010. O grupo apresentou municípios presentes em todas as regiões do país, além de algumas capitais da região norte: Porto Velho; Rio Branco; Boa Vista e ACP de Macapá. No ano de 2010, a configuração do grupo 5 apresentou variação, com a saída, principalmente, de municípios do sul e sudeste e entrada de mais municípios do norte e nordeste, tornando-se um pouco mais homogêneo do que no período anterior.

As taxas para tal grupo foram baixas se comparadas aos outros, o que indica que ele não pode ser considerado dinâmico em termos de criatividade. O mesmo ocorre para o grupo 6, que apresentou os piores indicadores do modelo. Tal grupo compreende basicamente cidades do interior do Norte e Nordeste do país, com algumas exceções em 2000 (uma cidade do Mato Grosso, uma de Minas Gerais e duas do Paraná) e com uma exceção em 2010, que foi a cidade de Manhuaçu.

A média do REGIC para tal grupo é a maior e, portanto, o mesmo é formado por cidades pouco influentes na rede urbana e ainda localizadas em regiões menos privilegiadas socioeconomicamente. Desta forma, era esperado que o grupamento menos dinâmico possuísse tais características, indo ao encontro do que é preconizado pela teoria. Desta forma, o grupo não mostra potencial para o surgimento de uma aglomeração produtiva, o que pode ser justificado por sua escala urbana menos expressiva e fora do polo nacional, inviabilizando o dinamismo do setor e demonstrando que a atividade criativa incipiente não possui força para impulsionar o seu desenvolvimento.

\section{Considerações finais}

O presente estudo afirma a ideia de que os aglomerados produtivos do setor criativo no Brasil têm a capacidade de gerar externalidades positivas para as firmas que os compõem, produzindo 
efeitos multiplicadores para suas regiões. Mais especificamente, a emergência de áreas especializadas em setores criativos constitui importante condicionante para o desenvolvimento econômico devido à sua capacidade de gerar bens e serviços de elevado valor agregado, estimular expressivos efeitos de encadeamento setoriais e espaciais; estimular a produção e a dispersão do conhecimento e da inovação em um ciclo virtuoso.

As atividades criativas são, em geral, intensivas em capital humano (e artístico), inovação, tecnologia, capacidade empreendedora, etc., fatores que tendem a se concentrar em ambientes urbanos e metropolitanos. Desta forma, a questão urbana é de especial interesse quando se trata do tema. Nessa linha, destacaram-se os argumentos de autores como Florida (2005), que salienta que as cidades tolerantes atraem as pessoas talentosas, que por sua vez atraem as firmas de tecnologia; e Storper e Venables (2004), que sugerem que o contato face-a-face e o "burburinho" gerado pelo mesmo, são os fatores chaves para a emergência dos aglomerados produtivos.

Ao delinear os padrões regionais específicos para os municípios brasileiros, o artigo apresentou um desenho geral das suas condições socioeconômicas entre 2000 e 2010, identificando as áreas com melhores indicadores (mais dinâmicas), bem como a importância relativa do setor criativo em tais localidades. Verificou-se que os indicadores censitários para o setor demonstraram expressiva heterogeneidade, além da sua concentração no eixo centro-sul do país ou nos grandes polos metropolitanos de suas diferentes macrorregiões. Uma vez identificadas essas particularidades, criouse uma tipologia regional para o setor criativo através do método de análise multivariada de agrupamentos. Tal método possibilitou a junção dos munícipios de acordo com sua similaridade em relação aos indicadores escolhidos.

Desta forma, a estimação do modelo encontrou três grupos principais, em termos de dinamismo do setor criativo no Brasil. Os três foram classificados, respectivamente, como grande polo criativo nacional, polo criativo nacional e polo criativo regional, demonstrando um potencial para formação de aglomerados produtivos do setor. As cidades que formaram tais grupamentos se destacam devido à sua infraestrutura urbana, robustez institucional, governança, presença de mão de obra especializada, posição na hierarquia urbana e proximidade ao eixo mais dinâmico do país. A análise da efetividade de existência desses aglomerados torna-se uma agenda de estudos futuros. Para tal, será preciso investigar a fundo o ambiente institucional, analisar o nível de especialização local, etc.

Por fim, o presente estudo pretende contribuir para a pauta de políticas públicas do país, tendo em vista a importância que o setor criativo possui no desencadeamento de efeitos econômicos positivos nas suas respectivas localidades. Sendo assim, o mapeamento das potenciais aglomerações criativas informa aos tomadores de decisão quais as áreas que necessitam de uma atenção especial, voltada para o estímulo direto ao seu surgimento. Por outro lado, tais informações possibilitam, também, identificar aquelas áreas que necessitam de políticas voltadas para os fatores que fomentam tais atividades, uma vez que o setor criativo ainda é incipiente.

\section{Referências bibliográficas}

BARROS, Ricardo Paes de. A efetividade do salário mínimo em comparação à do Programa Bolsa Família como instrumento de redução da pobreza e da desigualdade. In: IPEA. Desigualdade de Renda no Brasil: uma análise da queda recente. 2. ed. Brasília: Ipea, 2007. cap. 34. p. 507-549. 
CEGOV. UFRGS. Atlas Econômico da Cultura Brasileira: metodologia I. Porto Alegre: UFRGS/CEGOV, 2017. 25p.

CEGOV. UFRGS. Produto 1: Revisão de modelos existentes e contribuições teóricas para a conta satélite de cultura, fundamentando opções metodológicas. Porto Alegre: UFRGS/CEGOV, 2016.

CORAZZA, Rosana Icassatti. Criatividade, inovação e economia da cultura: abordagens multidisciplinares e ferramentas analíticas. Revista Brasileira de Inovação, Campinas, v. 12, n. 1, p. 207-231, jun. 2013.

FIRJAN. Mapeamento da indústria criativa no Brasil: ambiente socioeconômico. Rio de Janeiro: FIRJAN, 2019. 24p.

FLORIDA, Richard. Cities and the creative class. New York: Routledge, 2005. 198p.

FLORIDA, Richard; ADLER, Patrick; MELLANDER, Charlotta. The city as innovation machine. Regional Studies, [s.1.], v. 51, n. 1, p.86-96, 15 dez. 2016. Informa UK Limited.

FUNDAÇÃO PARQUE TECNOLÓGICO DA PARAÍBA (PaqTcPB). Homepage PaqTcPB. 2018. Disponível em: http://www.paqtc.org.br/. Acesso em: 1 fev. 2018.

GOLGHER, André Braz. As cidades e a classe criativa no Brasil: diferenças espaciais na distribuição de indivíduos qualificados nos municípios brasileiros. Rev. Bras. Estud. Popul., São Paulo, v. 25, n. 1, p.109-129, 2008.

GOLGHER, André Braz. A distribuição de indivíduos qualificados nas regiões metropolitanas brasileiras: a influência do entretenimento e da diversidade populacional. Nova Economia, Belo Horizonte, v. 21, n. 1, p.109-134, jan. 2011.

HOWKINS, John. Creative economy: how people make money from ideas. Penguin Global, 2002 [2001].

INSTITUTO BRASILEIRO DE GEOGRAFIA E ESTATÍSTICA (IBGE). Comissão Nacional de Atividades Econômicas. 2017. Disponível em: http://cnae.ibge.gov.br/classificacoes/portema/atividades-economicas/ classificacao-nacional-de-atividades-economicas. Acesso em: 30 mar. 2017.

INSTITUTO BRASILEIRO DE GEOGRAFIA E ESTATÍSTICA (IBGE). Microdados do Censo 2000. 2001. Disponível em: http://downloads.ibge.gov.br/downloads_estatisticas.htm\#. Acesso em: 3 maio 2017.

INSTITUTO BRASILEIRO DE GEOGRAFIA E ESTATÍSTICA (IBGE). Microdados do Censo 2010. 2011. Disponível em: http://www.ibge.gov.br/home/estatistica/populacao/censo2010/resultados gerais amostra/resultado S_gerais_amostra_tab_uf_microdados.shtm. Acesso em: 3 maio 2017.

INSTITUTO BRASILEIRO DE GEOGRAFIA E ESTATÍSTICA (IBGE). Regiões de Influência das Cidades: 2007. Rio de Janeiro: Ibge, 2008. 201p. 
Indústrias criativas no Brasil: mapeamento de aglomerações produtivas potenciais e sua contribuição para o desenvolvimento local

INSTITUTO DE PESQUISA ECONÔMICA APLICADA (IPEA). Desafios do Desenvolvimento: o que é? Índice de Gini. 2004. Disponível em: http://www.ipea.gov.br/desafios/index.php?option= com_content\&id=2048: catid=28\&Itemid=23. Acesso em: 21 jun. 2017.

MACHADO, Ana Flávia; SIMÕES, Rodrigo Ferreira; DINIZ, Sibelle Cornélio. Urban amenities and the development of creative clusters: the case of Brazil. Current Urban Studies, [s.1.], v. 1, n. 4, p. 92-101, 2013. Scientific Research Publishing, Inc.

MINGOTI, Sueli Aparecida. Análise de agrupamentos (cluster). In: MINGOTI, Sueli Aparecida. Análise de dados através de métodos de estatística multivariada: uma abordagem aplicada. Belo Horizonte: Editora Ufmg, 2007. cap. 6. p. 155-211.

NOVA SCOTIA. The Creative Nova Scotia Leadership Council. Creative Economy Literature Review. Nova Scotia: The Creative Nova Scotia Leadership Council, 2012. 58p.

OLIVEIRA, João Maria de; ARAUJO, Bruno Cesar de; SILVA, Leandro Valério. Panorama da economia criativa no Brasil. Brasília: Ipea, 2013. 54p. (Texto para Discussão, n. 1880).

REIS, Ana Carla Fonseca. Cidades criativas: da teoria à prática. São Paulo: Sesi-SP, 2012. 236p.

RESTREPO, Felipe Buitrago; MÁRQUEZ, Iván Duque. La economía naranja: una oportunidad infinita. New York: Banco Interamericano de Desarrollo, 2013. 244p.

ROCHA, Sonia. O Programa Bolsa Família: evolução e efeitos sobre a pobreza. Economia e Sociedade, Campinas, v. 20, n. 1 (41), p. 113-139, abr. 2011.

RUEDIGER, Marco Aurélio et al. A economia criativa e de alta tecnologia do Brasil: sumário executivo. Rio de Janeiro: FGV, 2015. 30p.

SILVA, Diana Lúcia Gonzaga da; SANTOS, Gervásio Ferreira dos; FREGUGLIA, Ricardo da Silva. Distribuição espacial dos efeitos de aglomeração sobre os retornos à educação no Brasil entre 1995 e 2008. Pesquisa e Planejamento Econômico, Rio de Janeiro, v. 46, n. 2, p.7-46, ago. 2016.

STORPER, Michael; VENABLES, Anthony J. Buzz: face-to-face contact and the urban economy. Journal of Economic Geography, [s.1.], v. 4, n. 4, p.351-370, Aug. 1, 2004. Oxford University Press (OUP).

TAYLOR, Calvin. Between culture, policy and industry: modalities of intermediation in the creative economy. Regional Studies, [s.1.], v. 49, n. 3, p.362-373, Jan. 8, 2013. Informa UK Limited.

UNCTAD. Creative Economy Report 2010. Usa: United Nations Development Programme (UNDP), 2010. 423p. 


\section{Arquivos Suplementares}

\section{A - Classificação CNAE das atividades econômicas consideradas como criativas}

Quadro 2

Classificação CNAE 2.0 de atividades criativas

\begin{tabular}{|c|c|}
\hline \multirow{2}{*}{$\begin{array}{l}\text { Código } \\
\text { CNAE }\end{array}$} & Descrição \\
\hline & Classificação UNCTAD \\
\hline 85029 & Ensino de esportes, de arte e cultura e de idiomas \\
\hline 94099 & Atividades de organizações associativas ligadas à cultura e à arte \\
\hline 91000 & Atividades ligadas ao patrimônio cultural e ambiental \\
\hline 73010 & Publicidade \\
\hline 90000 & Atividades artísticas, criativas e de espetáculos \\
\hline 74000 & Atividades de design e decoração de interiores, atividades fotográficas e similares \\
\hline 58000 & Edição e edição integrada à impressão \\
\hline 18000 & Impressão e reprodução de gravações \\
\hline 63000 & Atividades de prestação de serviços de informação \\
\hline 59000 & Atividades cinematográficas, produção de vídeos e de programas de televisão, gravação de som e de música \\
\hline 60002 & Atividades de televisão \\
\hline 60001 & Atividades de rádio \\
\hline 71000 & Serviços de arquitetura e engenharia e atividades técnicas relacionadas; testes e análises técnicas \\
\hline 73020 & Pesquisas de Mercado e Opinião Pública \\
\hline 72000 & Pesquisa e desenvolvimento científico \\
\hline 93020 & Atividades de recreação e lazer \\
\hline \multirow[t]{2}{*}{62000} & Atividades dos serviços de tecnologia da informação \\
\hline & Serviços Diversificados \\
\hline 35010 & Geração, transmissão e distribuição de energia elétrica \\
\hline 35021 & Produção e distribuição de combustíveis gasosos por redes urbanas \\
\hline 35022 & Produção e distribuição de vapor, água quente e ar condicionado \\
\hline 53001 & Atividades de correio \\
\hline 53002 & Atividades de malote e de entrega \\
\hline 64000 & Serviços financeiros \\
\hline 65000 & Seguros e previdência privada \\
\hline 66001 & Atividades auxiliares dos serviços financeiros \\
\hline 66002 & Atividades auxiliares dos seguros, da previdência complementar e dos planos de saúde \\
\hline 68000 & Atividades imobiliárias \\
\hline 69000 & Atividades jurídicas, de contabilidade e de auditoria \\
\hline 70000 & Atividades de consultoria em gestão empresarial \\
\hline 75000 & Atividades veterinárias \\
\hline 78000 & Seleção, agenciamento e locação de mão-de-obra \\
\hline 82001 & Serviços de escritório e apoio administrativo \\
\hline 82002 & Atividades de tele atendimento \\
\hline 82003 & Atividades de organização de eventos, exceto culturais e esportivos \\
\hline \multirow[t]{2}{*}{82009} & Outras atividades de serviços prestados principalmente às empresas \\
\hline & Atividades Correlacionadas \\
\hline 99000 & Organismos internacionais e outras instituições extraterritoriais \\
\hline 85014 & Educação superior \\
\hline 86001 & Atividades de atendimento hospitalar \\
\hline 86002 & Atividades de atenção ambulatorial executadas por médicos e odontólogos \\
\hline 86003 & Atividades de serviços de complementação diagnóstica e terapêutica \\
\hline 86004 & Atividades de profissionais da área de saúde, exceto médicos e odontólogos \\
\hline 86009 & Atividades de atenção à saúde humana, não especificadas anteriormente \\
\hline 86999 & Atividades de saúde não especificadas \\
\hline 61000 & Telecomunicações \\
\hline 32002 & Fabricação de instrumentos musicais \\
\hline
\end{tabular}

Fonte: As autoras (2018). Baseado em dados de IBGE (2017). 
Indústrias criativas no Brasil: mapeamento de aglomerações produtivas potenciais e sua contribuição para o desenvolvimento local

\section{B - Descrição dos índices utilizados na análise dos padrões regionais específicos para os municípios brasileiros}

Rendimento médio do trabalho principal: $\mathrm{O}$ indicador é uma média municipal para o rendimento bruto proveniente do trabalho principal, cujos valores estão deflacionados com base no ano de 2016.

Índice de Gini: Segundo IPEA (2004), o coeficiente aponta a diferença entre os rendimentos dos mais pobres e dos mais ricos, sendo que o valor zero representa a situação de igualdade e o valor um é quando uma só pessoa detém toda a riqueza (extrema desigualdade).

Taxa de Formalidade: A taxa de formalidade representa a proporção do pessoal ocupado em todos os setores da economia que possui um trabalho formal (razão entre a quantidade total de trabalhadores formais e a quantidade total da população ocupada), em cada município.

Taxa de Formalidade no Setor Criativo: A taxa diz respeito à proporção do pessoal ocupado apenas no setor criativo (atividades de cultura e inovação, serviços diversificados e atividades correlacionadas) que possui um vínculo formal.

Taxa de qualificação superior no setor criativo: A taxa é a proporção de pessoal ocupado no setor criativo (atividades de cultura e inovação, serviços diversificados e atividades correlacionadas) com instrução maior ou igual a 15 anos de estudo e que cursam ou cursaram o ensino superior.

Taxa de qualificação em nível de pós-graduação no setor criativo: A taxa de qualificação em nível de pósgraduação no setor criativo é a proporção de pessoas ocupadas no setor (atividades de cultura e inovação, serviços diversificados e atividades correlacionadas) com instrução maior ou igual a 15 anos de estudo e que cursam ou cursaram mestrado e/ou doutorado.

Proporção de pessoal ocupado no setor criativo: O indicador é a razão entre o total do pessoal ocupado nos setores classificados como criativos (atividades de cultura e inovação, serviços diversificados e atividades correlacionadas) e o total do pessoal ocupado da economia.

Taxa de cursos superiores criativos: O indicador se refere à proporção de pessoal ocupado no setor criativo que frequenta ou frequentou cursos de graduação relacionados à criatividade. As formações superiores consideradas foram: artes, ciências sociais e comportamentais, jornalismo e informação, comércio e administração, computação, engenharia e profissões correlatas, arquitetura e construção, veterinária e saúde. 